\title{
Anger expression among Danish cyclists and drivers: A comparison based on mode specific anger expression inventories
}

\author{
Møller, Mette; Haustein, Sonja
}

Published in:

Accident Analysis and Prevention

Link to article, DOI:

10.1016/j.aap.2017.09.016

Publication date:

2017

Document Version

Peer reviewed version

Link back to DTU Orbit

Citation (APA):

Møller, M., \& Haustein, S. (2017). Anger expression among Danish cyclists and drivers: A comparison based on mode specific anger expression inventories. Accident Analysis and Prevention, 108, 354-360.

https://doi.org/10.1016/j.aap.2017.09.016

\section{General rights}

Copyright and moral rights for the publications made accessible in the public portal are retained by the authors and/or other copyright owners and it is a condition of accessing publications that users recognise and abide by the legal requirements associated with these rights.

- Users may download and print one copy of any publication from the public portal for the purpose of private study or research.

- You may not further distribute the material or use it for any profit-making activity or commercial gain

- You may freely distribute the URL identifying the publication in the public portal

If you believe that this document breaches copyright please contact us providing details, and we will remove access to the work immediately and investigate your claim 


\title{
Anger expression among Danish cyclists and drivers: A comparison based on mode specific anger expression inventories
}

\author{
M. Møller*, S. Haustein \\ Technical University of Denmark, Department of Management Engineering, DK-2800 Kgs., Lyngby, Denmark
}

\section{A R T I C L E I N F O}

\section{Keywords:}

Driving anger

Aggressive driving

DAX

Anger expression

Attitudes

\begin{abstract}
A B S T R A C T
Based on the short form of the driving anger expression inventory (DAX-short, 15-item), the present study developed an adapted version of the DAX for cyclists (CAX, 14 items). The data basis was an online survey of 2000 inhabitants of Denmark. A principle component analysis on the translated DAX-short confirmed the 4factor solution of the original study differentiating between (1) personal physical aggressive expression, (2) use of a vehicle to express anger, (3) verbal aggressive expression and (4) adaptive/constructive expression. In case of cycling, the factor "use of a vehicle to express anger" only included one item and was left out. Based on the results, reliable subscales were developed. Drivers scored higher in verbal aggressive expression than cyclists, while there was no significant difference in constructive expression. The subscales for drivers and cyclists showed significant relations to age, gender, self-reported aggressive behaviours and traffic fines: Women scored for instance lower in physical expression, while older people scored higher in constructive expression. The effect of age and gender on anger expression among drivers and cyclists remained significant when controlling for exposure and other factors in linear regression analyses. These analyses also showed a relationship between a positive attitude towards driving and higher levels of anger expression among drivers, while this was not the case for cyclists.
\end{abstract}

\section{Introduction}

According to Shinar (1998) awareness of driver anger and aggression stems back at least to the middle of the last century and the work by Tillman and Hobbs (1949) on accident involvement among taxi drivers. Since then many studies have looked into the prevalence and aetiology of driver aggression from different perspectives. Examples include road anger as an example of violence towards strangers (e.g. Harding et al., 1998), perceived status and threat (e.g. Lu et al., 2013; McGarva and Steiner, 2000); traffic culture characteristics (e.g. Matsumoto et al., 2010; Parker et al., 2002; Sullman, 2006), personality, mental illness and other individual characteristics (e.g. Björklund, 2008; Bogdan et al., 2016; Dahlen et al., 2005; Fong et al., 2001; Lajunen and Parker, 2001) as well as vehicle and traffic situation related characteristics (e.g. Fraine et al., 2007; O'Brien et al., 2004; Shinar and Compton, 2004). In the late 1980'ies and early 1990'ies the concept of road rage was introduced (Fong et al., 2001) thereby creating the impression of the occurrence of a new phenomenon and causing conceptual confusion (Dula and Geller, 2003).

In this study, data on anger expression among drivers and cyclists is based on the Driving Anger Expression Inventory (DAX) (see
Deffenbacher et al., 2002), a widely used questionnaire specifically developed to measure expression of driving related anger. The original DAX included sixty-two items, but recently Stephens and Sullman (2014) developed a 15-item version (DAX-short). The development of the DAX was inspired by findings derived in the late 1980'ies/early 1990 'ies where studies on anger showed that anger is not only a result of a general individual trait-based tendency to experience anger across different situations but can also be triggered off by specific situational factors. To explore this and specifically measure driving related anger the Driving Anger Scale (DAS) was developed (Deffenbacher et al., 2016), and was later supplemented by the DAX to measure the actual expression of driving related anger. According to Deffenbacher et al. (2001) anger is conceptually related to aggression as also indicated by the labelling of the forms in which drivers express their anger for example "verbally aggressive expression" and "physical aggressive expression" (see Deffenbacher et al., 2002). In line with the general understanding of driver aggression (Wickens et al., 2013), the phrasing of the specific DAX-items (see Table 3) indicates that the aggressive expressions are seen as deliberate and directed towards other road users either directly by behaviours such as "scare the other road user" or indirectly by behaviours such as "tell myself to ignore it". However,

\footnotetext{
* Corresponding author.

E-mail address: mette@dtu.dk (M. Møller).
} 
driver aggression as measured by DAX is different from aggressive driving, which often does not include the adaptive/constructive element and is limited to behaviours performed while driving (e.g. Dula and Geller, 2003; Rowden et al., 2016).

As is the case with many aspects of road user behaviour, research on anger and aggression in traffic has mainly focused on drivers, driver behaviour, and driver related situations. Even in the rare studies including cyclists, the perspective of the driver is the main focus (e.g. Fruhen and Flin, 2015). However, with increasing attempts to promote cycling with reference to individual and societal benefits such as increased health (e.g. Oja et al., 2011; Tainio et al., 2016), environmental benefits (e.g. Xia et al., 2015), and reduced congestion (e.g. Project, 2016) knowledge on anger expression among cyclists is increasingly relevant. Beyond that, the increased awareness of negative consequences and challenges related to different types of emotional stress triggered off by cyclists and drivers sharing the road (e.g. Aldred, 2013; Kaplan and Prato, 2016) and driver harassment directed towards cyclists (e.g. Heesch et al., 2011) clearly indicate the relevance of knowledge on the occurrence on cyclist anger and possible differences between driver and cyclist anger expression in order to support safe and peaceful interaction between cyclists and drivers sharing the road.

However, knowledge on driver anger and aggression may only partly be transferable to cyclists as earlier studies indicate the aetiology and prevalence to be multifactorial, and partly linked to the vehicle. While individual characteristics, such as personality, may influence driver and cyclist anger expression in similar ways, the influence from vehicle characteristics and perceived status may lead to differences in anger expressions. Despite limited knowledge on cyclists' anger and aggression, the relevance of specific knowledge on cyclist anger and aggression is supported by a recent study in which motorcyclist and driver aggression was compared (Rowden et al., 2016). Results identified both person and vehicle related differences between motorcyclist aggression and driver aggression. Thus, people were less likely to behave aggressively when riding a motorcycle than when driving a car, indicating a tendency to adapt to a defensive behavioural strategy as a response to a perception of inferior status or vulnerability, which is in line with previous studies (e.g., Gwyther and Holland, 2014; Klein et al., 2011; McGarca and Steiner, 2000). Cyclists are generally categorized as vulnerable road users and a defensive behavioural strategy similar to the behavioural strategy of motorcyclists could therefore be expected although examples of cyclist aggression do also exist (e.g. Lloyd, 2016). In terms of status, there may be smaller differences between drivers and cyclists in Denmark as compared to other countries, as Denmark is a country with a pronounced cycling culture (cf. Carstensen and Ebert, 2012; Haustein and Nielsen, 2016). This may lead to a more similar level of aggression between both groups. However, until now, very little research on cyclist anger exists, leaving a strong need for research in this area.

The purpose of this study was to compare self-reported expression of anger among Danish drivers and cyclists. The measurement of anger expression was based on a short version of the Driving Anger Expression

Table 1

Driving and cycling frequency of the sample.

\begin{tabular}{llllll}
\hline & \multicolumn{2}{l}{ Car (as driver) } & & \multicolumn{2}{l}{ Cycle } \\
\cline { 2 - 3 } \cline { 5 - 6 } & $N$ & & & $N$ & $\%$ \\
\hline Everyday & 584 & 29.2 & & 360 & 18.0 \\
4-6 days per week & 413 & 20.7 & & 264 & 13.2 \\
2-3 days per week & 240 & 12.0 & & 210 & 10.5 \\
Weekly & 127 & 6.4 & & 148 & 7.4 \\
1-3 days per month & 103 & 5.2 & & 167 & 8.4 \\
Less than monthly & 150 & 7.5 & & 345 & 17.3 \\
Never & 383 & 19.2 & & 506 & 25.3 \\
Total & 2000 & 100.0 & & 2000 & 100.0 \\
\hline
\end{tabular}

Inventory (DAX-short) (Stephens and Sullman, 2014), which includes four categories of anger expression (verbal aggressive expression, personal physical aggressive expression, use of vehicle to express anger, adaptive/constructive expression) as well as a total aggressive expression index. The short version was preferred to the original to avoid exhaustion of the participants due to the inclusion of other variables of key importance to the study. To measure cyclist anger expression an adapted version of the DAX-short was developed, the cyclist anger expression inventory (CAX).

\section{Method}

\subsection{Procedure and participants}

Data were collected based on an online panel of the market research institute EPINION on behalf of the Danish Road Safety Council in September 2016. The panel ("Danmarkspanelet") consists of 244,568 members (with a monthly inflow of 7510 new panellists) covering all regions of Denmark. Panellists get incentives in form of regular participation in lotteries (see Epinionglobal.com). Two thousand individuals aged between 18 and 75 years completed an online questionnaire (mean age: 48 years; SD: 16.5). About half of the participants were female $(52.5 \%)$, and $62.4 \%$ were married and/or lived together with a partner. The level of education was a bit higher than in the general population of Denmark with only $9.3 \%$ who finalised school after the 9th or 10th grade without any further education (=basic education), and $18.1 \%$ with long further education (5 years or more, e.g. master degree). ${ }^{1}$

Table 1 shows participants' car use frequency as driver and their cycling frequency. About half of the sample (49\%) cycles weekly or more, while a quarter never cycles; $68 \%$ drive a car at least weekly, while about one fifth (19\%) never drive.

\subsection{Material}

The use of different modes of transport (car as driver, public transport, conventional bike, e-bike, moped, motorcycle, walking) was assessed on a seven point frequency scale ("every day" - "never"). Attitudes towards driving and cycling were measured with four items each, asking participants how stressed they felt about driving and cycling, as well as about their attitude towards driving and cycling in terms of excitement and autonomy. The eight items which were assessed on a five point Likert scale ( 1 = "totally disagree" - 5 = "totally agree") were merged to four means scales with acceptable internal consistencies (car positive: $\alpha=0.69$; car stress: $\alpha=0.73$; bike positive: $\alpha=0.80$; bike stress: $\alpha=0.80$ ).

Involvement in traffic violations was assessed based on self-reported information regarding the last 12 months on being penalized of "speeding" as a driver, and "rule-breaching behaviours as a cyclist".

With regard to anger, the participants were asked about their involvement in five specific situations as victim and/or aggressor within the past 12 months. The specific situations included: (1) "yelling"; (2) "getting/giving the finger"; (3) "threats"; (4) "hitting/kicking a vehicle" and (5) "hitting/kicking a person". If involved, participants were further asked how many times it had happened as well as about the used transport mode (own/counterpart) in the latest situation within each category. Questions on anger expressions included the 15 items of the DAX-short (Stephens and Sullman, 2014) translated to Danish, as well as an adapted version of the items to cyclists (CAX; see Table 3). For one item ('roll down the window to communicate my anger') an adaption to cyclists was not possible, and the item was therefore not included in the

\footnotetext{
${ }^{1}$ In Denmark in 2017, $20.7 \%$ of the population aged $20-69$ years had only basic education, while $10.4 \%$ had a long further education (own calculations based on Statistics Denmark, http://www.statistikbanken.dk).
} 
cyclist version of the DAX-short. The items were assessed on a five point Likert scale ( 1 = "never" - $5=$ "always"). Participants who did not drive were not asked to answer the DAX items, and participants who did not cycle were not asked to answer the CAX items.

Finally, the questionnaire included the following demographic variables: age, gender, income, education, civil status, and postal code.

\subsection{Analysis}

Principal component analyses with Direct Oblim Rotation were conducted to explore the factor structure of the short form of the DAX and CAX. To confirm the factorial structure of the newly developed CAX scales, we used confirmative factor analysis. Differences between related DAX and CAX subscales were tested by paired $t$-tests and relations were examined by Pearson's correlations. The relation of DAX and CAX subscales to demographic variables, self-reported behaviours and traffic violations were tested by $F$-tests. Linear regression analysis was used to explore the effect of single variables on driving and cycling aggression while simultaneously controlling for the effect of other variables, such as driving and cycling frequency.

\section{Results}

\subsection{Involvement in anger expression episodes}

One third of the sample (33.9\%) reported to have experienced at least one of five requested aggressive interactions with other road users within the past twelve month as a victim, and about a quarter (24.5\%) as aggressor. Table 2 shows the percentages for each situation as well as the mean frequencies for situations reported by at least thirty participants. More than one fifth of the sample was yelled at by other road users and got the finger within the past 12 month. Almost one out of hundred was hit by other road users. For all situations except hitting/ being hit, the participants more often reported to be the victim of other people's anger expressions than being the aggressor. People involved in the requested situations were additionally asked which mode of transport they used in the latest situation and which mode their counterpart used. In case of giving/getting the finger, more than half of the reported situations happened exclusively among car drivers. Yelling at other road users was additionally common among cyclist both with drivers and other cyclists as counterparts. In the case of hitting other road users' vehicle drivers most often experienced that cyclists or pedestrians hit their car.

Table 3 shows the means and standard deviations of the DAX items
Table 3

DAX and CAX itefms.

\begin{tabular}{|c|c|c|c|c|}
\hline \multirow[t]{2}{*}{ DAX and CAX items } & \multicolumn{2}{|l|}{ DAX } & \multicolumn{2}{|l|}{ CAX } \\
\hline & Mean & SD & Mean & SD \\
\hline $\begin{array}{l}\text { I make negative comments about the road user } \\
\text { aloud }\end{array}$ & 2.37 & 0.92 & 1.82 & 0.91 \\
\hline I swear at the other road user aloud & 2.23 & 0.95 & 1.73 & 0.90 \\
\hline I yell at the other road user & 1.46 & 0.78 & 1.45 & 0.78 \\
\hline $\begin{array}{l}\text { I get out/of the car/bicycle and tell the other driver } \\
\text { off }\end{array}$ & 1.08 & 0.43 & 1.14 & 0.54 \\
\hline I get out/of the car/bicycle to have a physical fight & 1.06 & 0.43 & 1.09 & 0.49 \\
\hline I roll down the window to communicate my anger & 1.14 & 0.51 & & \\
\hline I try to scare the other road user & 1.09 & 0.45 & 1.11 & 0.52 \\
\hline I drive right up to the other road user & 1.27 & 0.60 & 1.18 & 0.60 \\
\hline I do to the other road users what they did to me & 1.22 & 0.56 & 1.19 & 0.61 \\
\hline I drive a lot faster & 1.42 & 0.75 & 1.41 & 0.85 \\
\hline $\begin{array}{l}\text { I think of positive solutions to deal with the } \\
\text { situation }\end{array}$ & 3.40 & 1.21 & 3.34 & 1.35 \\
\hline I tell myself it's not worth getting mad at & 3.70 & 1.09 & 3.64 & 1.25 \\
\hline I tell myself it's not worth getting involved & 3.87 & 1.14 & 3.70 & 1.27 \\
\hline I accept there are frustrating situations & 3.70 & 1.02 & 3.59 & 1.19 \\
\hline I tell myself to ignore it & 3.73 & 1.05 & 3.66 & 1.21 \\
\hline
\end{tabular}

Note: 1 = never; 5 = always; $N($ DAX) $=1617 ; N($ CAX $)=1533$. People who answered to never drive/cycle did not get the respective questions.

and their adaption to cycling (CAX). For both cycling and driving, constructive behaviours are much more common than aggressive behaviours and show higher standard deviations.

\subsection{Driving and cycling anger expression scales}

A principal component analysis with Direct Oblim Rotation was carried out. The scree plot confirmed the suitability of a 4-factor solution for both driving and cycling anger expression. In case of driving, all items showed the highest loading on the factor they were expected to. In case of cycling, only one item ("I drive a lot faster") had a high loading on the last factor ("use of a vehicle to express anger"), while the other two items that were supposed to belong to this factor had a higher loading on factor 1 ("personal physical aggressive expression"). This is not surprising as the possibilities to use a bike to express anger without using physical aggression are rather restricted. The items "I drive a lot faster" was thus excluded from further analysis, leading to only three factors for cycling anger expression. Based on the results, mean scales were calculated including the items with loadings $>0.6$. on each factor. In addition, total aggressive aggression scales were calculated

Table 2

Involvement in road anger situations as victim and as aggressor in the past 12 months.

\begin{tabular}{|c|c|c|c|c|c|c|c|c|}
\hline \multirow[t]{2}{*}{ Situation } & \multicolumn{2}{|c|}{ Occurrence within past 12 month } & \multicolumn{6}{|c|}{$\begin{array}{l}\text { Own-counterpart's role per situation (percentages for combinations that account for more than } 10 \% \text { of the } \\
\text { situation) }\end{array}$} \\
\hline & Involvement (\%) & $\begin{array}{l}\text { Mean } \\
\text { frequency }\end{array}$ & Driver-driver & Cyclist-cyclist & Cyclist-driver & Driver-cyclist & Driver-pedestrian & Cyclist-pedestrian \\
\hline $\begin{array}{l}\text { I was yelled at by other road } \\
\text { users }\end{array}$ & 22.0 & 2.5 & 31.7 & 20.0 & $13.4 \%$ & & & \\
\hline I got the finger & 20.7 & 2.3 & 67.6 & & & & & \\
\hline $\begin{array}{l}\text { I was threatened by other road } \\
\text { users }\end{array}$ & 6.9 & 2.0 & 57.0 & & & & & \\
\hline $\begin{array}{l}\text { My vehicle was hit by other } \\
\text { road users }\end{array}$ & 4.4 & 5.5 & 13.0 & & & 18.8 & 17.4 & 13.0 \\
\hline I was hit by other road users ${ }^{\mathrm{a}}$ & 0.7 & & & & & & & \\
\hline I yelled at other road users & 17.7 & 4.9 & 36.6 & 17.2 & 15.6 & & & \\
\hline I gave the finger & 12.6 & 4.0 & 65.9 & & & & & \\
\hline I threatened other road users ${ }^{\mathrm{a}}$ & 1.2 & & & & & & & \\
\hline I hit others' vehicle ${ }^{a}$ & 1.4 & & & & & & & \\
\hline I hit other road users ${ }^{a}$ & 0.5 & & & & & & & \\
\hline
\end{tabular}

Note:

${ }^{a}$ too few cases $(<30)$ for further analysis. 
Table 4

Principal component analysis of DAX and CAX items.

\begin{tabular}{|c|c|c|c|c|c|c|c|c|}
\hline & \multicolumn{4}{|c|}{ Driving anger expression (DAX) } & \multicolumn{4}{|c|}{ Cycling anger expression (CAX) } \\
\hline & Physical & Constructive & Verbal & Vehicle & Physical & Constructive & Verbal & Vehicle \\
\hline I make negative comments about the other road user aloud & -0.13 & 0.01 & 0.89 & 0.07 & -0.07 & 0.01 & 0.93 & 0.02 \\
\hline I swear at the other road user aloud & -0.01 & 0.02 & 0.89 & 0.03 & -0.06 & 0.01 & 0.93 & 0.03 \\
\hline I yell at the other road user & 0.41 & -0.09 & 0.61 & -0.05 & 0.27 & -0.04 & 0.71 & -0.05 \\
\hline I get out/off the car/bicycle and tell the other driver off & 0.95 & 0.00 & -0.01 & -0.01 & 0.91 & 0.00 & 0.06 & -0.08 \\
\hline I get out/of the car/bicycle to have a physical fight & 0.94 & 0.03 & -0.03 & 0.02 & 0.98 & 0.02 & -0.04 & -0.03 \\
\hline I roll down the window to communicate my anger & 0.85 & -0.01 & 0.05 & 0.03 & & & & \\
\hline I try to scare the other road user & 0.79 & -0.02 & -0.02 & 0.18 & 0.95 & 0.00 & -0.01 & -0.02 \\
\hline I drive right up to the other road user & 0.18 & 0.00 & 0.04 & 0.71 & 0.82 & 0.00 & 0.00 & 0.11 \\
\hline I do to the other road users what they did to me & 0.26 & -0.01 & 0.01 & 0.63 & 0.74 & -0.02 & 0.03 & 0.20 \\
\hline I drive a lot faster & -0.13 & -0.01 & 0.03 & 0.91 & 0.04 & 0.01 & 0.02 & 0.96 \\
\hline I think of positive solutions to deal with the situation & 0.03 & 0.69 & -0.06 & 0.09 & 0.03 & 0.76 & 0.02 & 0.03 \\
\hline I tell myself it's not worth getting mad at & 0.06 & 0.85 & -0.07 & -0.04 & 0.01 & 0.94 & -0.01 & -0.04 \\
\hline I tell myself it's not worth getting involved & -0.03 & 0.84 & 0.09 & -0.03 & -0.02 & 0.93 & 0.03 & -0.02 \\
\hline I accept there are frustrating situations & -0.06 & 0.78 & 0.09 & 0.00 & -0.01 & 0.87 & -0.01 & 0.02 \\
\hline I tell myself to ignore it & 0.02 & 0.84 & -0.04 & -0.05 & 0.00 & 0.91 & -0.03 & 0.00 \\
\hline Cronbachs alpha single scales & 0.93 & 0.86 & 0.79 & 0.75 & 0.94 & 0.93 & 0.86 & - \\
\hline Cronbachs alpha total aggression & & & & 0.85 & & & & 0.89 \\
\hline
\end{tabular}

for driving and cycling based on items that loaded on all factors except for factor 2 ("adaptive/constructive expression"). All mean scales have acceptable internal consistencies as shown by Cronbach's alphas between 0.75 and 0.93 (see Table 4). For the newly created CAX scales, we conducted a confirmatory factors analysis to confirm the factorial structure of the three remaining factors. Then model produced an acceptable fit as indicated by the following fit-statistics: $\mathrm{CFI}=0.966$; RMSEA $=0.068$ (90\% C.I. $=0.063-0.073)$.

When comparing the means of the DAX and CAX subscales (see Table 5), we find that individuals score higher in verbal and total anger expression as drivers than as cyclists but do not differ significantly with regard to constructive anger expression. As cyclists, individuals score higher in physical aggression than as drivers but although the difference becomes statistically significant, it is so small that it is not considered relevant as confirmed by the low effect size. In addition, it has to be taken into account that the CAX physical aggression scale includes two items that in DAX belongs to the "use of a vehicle to express anger" scale, which is not considered here, as there is not comparable scale in CAX. The physical aggression scales in CAX and DAX are thus not totally comparable.

Despite the differences in level, the CAX and DAX scales are highly correlated. The constructive scales have the highest correlation (.70), the verbal scales the lowest (.52).

\subsection{DAX and CAX by demographic variables and attitudes}

Table 6 shows the relation of DAX and CAX subscales to demographic variables. Though some of the group differences are significant, most of the effect sizes $\left(\mathrm{Eta}^{2}\right)$ are so low (between 0.00 and 0.02 ), that we do not consider them as relevant. The only effect sizes above 0.02 are found for age groups. Older drivers are more constructive $\left(\mathrm{Eta}^{2}=0.05\right)$ and less verbally aggressive $\left(\mathrm{Eta}^{2}=0.03\right)$. In post-hoc tests (Bonferroni), the oldest age group differs significantly from the three middle age groups $(p<0.05)$, and tendentiously from the youngest group $(p=0.08)$ with regard to verbally aggressive behaviour. With regard to constructive behaviour, the two oldest age groups differ significantly from the three younger age groups $(p<0.01)$.

To get a clearer picture about the determinants of total driving and cycling aggression, we conducted two linear regression analyses, one with driving and one with cycling aggression as dependent variable. As predictors, we included all demographic variables and additionally the frequency of driving and cycling and the attitudes towards driving and cycling. As Table 7 shows, for both driving and cycling, anger expression decreases with increasing age, though this relation is more pronounced for drivers. Male gender is significantly related to higher overall aggression though the relation is not very pronounced as indicated by a beta value below 0.1. Education, income and regional factors do not have a significant impact. Besides the influence of age and gender, the analyses show that cycling frequency and perceived stress while cycling increases anger expression among cyclists just as driving frequency and driving stress increases anger expression among drivers. However, while a positive attitude towards driving increases driver anger expression, this is not the case for cycling, meaning that people who are enthusiastic about driving express more anger while enthusiastic cyclists do not.

However, the explained variance of driving anger expression $\left(R^{2}=0.09\right)$ and in particular cycling anger expression $\left(R^{2}=0.06\right)$ is very low. Thus demographics, driving and cycling frequencies and attitudes have only a limited value in explaining differences in anger expression among road users.

\subsection{DAX and CAX by self-reported behaviours and traffic violations}

As Table 8 shows, drivers who received a ticket for speeding within

Table 5

Comparison of DAX and CAX scores.

\begin{tabular}{|c|c|c|c|c|c|c|c|}
\hline & \multicolumn{2}{|l|}{ DAX } & \multicolumn{2}{|l|}{ CAX } & \multirow{2}{*}{$\begin{array}{l}\text { paired } t \text {-test } \\
t\end{array}$} & \multirow{2}{*}{$\begin{array}{l}\text { Effect size } \\
\text { Cohen's } d\end{array}$} & \multirow{2}{*}{$\begin{array}{l}\text { Pearson Corr. DAX-CAX } \\
r\end{array}$} \\
\hline & Mean & SD & Mean & $\mathrm{SD}$ & & & \\
\hline Verbal & 2.04 & 0.75 & 1.66 & 0.76 & $17.75^{* * *}$ & 0.40 & $0.52^{k * * *}$ \\
\hline Physical & 1.10 & 0.41 & 1.14 & 0.50 & $-3.63^{* * * *}$ & 0.09 & $0.60^{* * * * *}$ \\
\hline Constructive & 3.63 & 0.87 & 3.59 & 1.12 & 1.80 & 0.04 & $0.70^{\text {*k***}}$ \\
\hline Total aggression & 1.45 & 0.43 & 1.34 & 0.52 & $9.24^{* * * *}$ & 0.23 & $0.61^{* * * *}$ \\
\hline
\end{tabular}

Note: 
Table 6

DAX and CAX by demographic variables.

\begin{tabular}{|c|c|c|c|c|c|c|c|c|c|}
\hline & & \multicolumn{4}{|l|}{ DAX } & \multicolumn{4}{|l|}{ CAX } \\
\hline & & Verbal & Physical & Con-structive & Total aggression & Verbal & Physical & Con-structive & Total aggression \\
\hline \multirow[t]{3}{*}{ Gender } & Men & 2.00 & 1.13 & 3.62 & 1.46 & 1.67 & 1.19 & 3.48 & 1.37 \\
\hline & Women & 2.04 & 1.06 & 3.73 & 1.41 & 1.66 & 1.10 & 3.68 & 1.31 \\
\hline & $F$-value & 1.11 & $11.48^{* *}$ & $6.17^{*}$ & 3.71 & 0.07 & $11.55^{\text {k* }}$ & $11.80^{\text {k.k }}$ & $4.85^{*}$ \\
\hline \multirow[t]{6}{*}{ Age } & 18-25 years & 1.99 & 1.16 & 3.36 & 1.48 & 1.58 & 1.23 & 3.39 & 1.36 \\
\hline & 26-35 years & 2.14 & 1.16 & 3.41 & 1.53 & 1.71 & 1.19 & 3.39 & 1.39 \\
\hline & $36-55$ years & 2.15 & 1.07 & 3.63 & 1.47 & 1.76 & 1.12 & 3.56 & 1.36 \\
\hline & 56-65 years & 1.96 & 1.07 & 3.85 & 1.39 & 1.65 & 1.10 & 3.68 & 1.31 \\
\hline & $66-75$ years & 1.80 & 1.08 & 3.89 & 1.34 & 1.52 & 1.13 & 3.85 & 1.27 \\
\hline & $F$-value & $14.29^{\text {k:k***}}$ & $2.93^{*}$ & $19.75^{\text {k*kik }}$ & $9.49^{* * * *}$ & $5.50^{* * 2 * k}$ & $2.97^{*}$ & $7.92^{\text {k*** }}$ & 2.18 \\
\hline \multirow[t]{5}{*}{ Edu-cation } & Basic education (9th or 10th grade) & 2.01 & 1.22 & 3.52 & 1.49 & 1.66 & 1.26 & 3.30 & 1.41 \\
\hline & Short further education & 2.05 & 1.11 & 3.60 & 1.47 & 1.62 & 1.15 & 3.55 & 1.33 \\
\hline & Medium further education & 2.00 & 1.07 & 3.74 & 1.42 & 1.66 & 1.12 & 3.65 & 1.32 \\
\hline & Long further education & 2.02 & 1.06 & 3.73 & 1.41 & 1.74 & 1.14 & 3.63 & 1.36 \\
\hline & $F$-value & 0.52 & $5.43^{\text {k** }}$ & $3.80^{*}$ & $2.30^{+}$ & 1.57 & $3.20^{*}$ & $3.98^{* * *}$ & 1.48 \\
\hline \multirow[t]{4}{*}{ Income } & up to 299.999 & 2.02 & 1.15 & 3.66 & 1.47 & 1.69 & 1.23 & 3.45 & 1.40 \\
\hline & $300.000-599.999$ & 2.03 & 1.08 & 3.67 & 1.43 & 1.68 & 1.14 & 3.60 & 1.34 \\
\hline & 600.000 and over & 2.06 & 1.08 & 3.72 & 1.45 & 1.68 & 1.11 & 3.71 & 1.32 \\
\hline & $F$-value & 0.35 & $3.29^{*}$ & 0.73 & 1.05 & 0.06 & $5.33^{\text {k** }}$ & $5.51^{* * *}$ & 2.39 \\
\hline \multirow[t]{3}{*}{ Copen-hagen } & Copenhagen & 1.98 & 1.07 & 3.53 & 1.40 & 1.91 & 1.20 & 3.53 & 1.46 \\
\hline & Outside Copenhagen & 2.02 & 1.10 & 3.69 & 1.44 & 1.63 & 1.13 & 3.59 & 1.32 \\
\hline & $F$-value & 0.41 & 0.50 & 3.82 & 1.10 & $19.03^{* x+k x}$ & 2.42 & 0.40 & $11.36^{* *}$ \\
\hline
\end{tabular}

Note:

$* * p<0.01$.

$* * * p<0.001$.

Table 7

Linear regression analyses explaining driving and cycling anger expression.

\begin{tabular}{|c|c|c|c|c|}
\hline & \multicolumn{2}{|c|}{ Driving anger expression } & \multicolumn{2}{|c|}{ Cycling anger expression } \\
\hline & Beta & $p$ & Beta & $p$ \\
\hline Age & -0.203 & 0.000 & -0.093 & 0.002 \\
\hline Gender (female) & -0.061 & 0.024 & -0.068 & 0.017 \\
\hline Education level & -0.042 & 0.140 & -0.004 & 0.882 \\
\hline $\begin{array}{l}\text { Living together with a } \\
\text { partner }\end{array}$ & 0.028 & 0.373 & 0.062 & 0.061 \\
\hline Income & -0.043 & 0.201 & -0.053 & 0.132 \\
\hline Copenhagen & -0.009 & 0.799 & 0.038 & 0.289 \\
\hline City size & 0.021 & 0.532 & -0.011 & 0.770 \\
\hline Cycling frequency & 0.016 & 0.594 & -0.101 & 0.003 \\
\hline Driving frequency & -0.147 & 0.000 & -0.047 & 0.187 \\
\hline Driving stress & 0.157 & 0.000 & & \\
\hline $\begin{array}{l}\text { Driving excitement and } \\
\text { autonomy }\end{array}$ & 0.132 & 0.000 & & \\
\hline Bike stress & & & 0.215 & 0.000 \\
\hline $\begin{array}{l}\text { Bike excitement and } \\
\text { autonomy }\end{array}$ & & & 0.044 & 0.181 \\
\hline$R^{2}$ & & 0.085 & & 0.057 \\
\hline
\end{tabular}

the past 12 month score higher in total aggression as driver. Cyclist who received a ticket for rule breaching behaviour score higher in verbal, physical and total aggression as a cyclist and in verbal anger expression as a driver. In addition, they show less constructive expression as a driver. All subscores were additionally significantly related to the selfreported behaviours of yelling at other road users and giving the finger (other types of anger expression not reported because of too few cases).

\section{Discussion}

The purpose of this study was to compare self-reported anger expression and involvement in road traffic anger episodes among drivers and cyclists in Denmark. For this purpose, a cyclist anger expression inventory $(\mathrm{CAX})$ was developed based on the driver anger expression inventory (DAX). The DAX showed the same factor structure in our study on Danish road users as in previous studies on drivers in the UK and Ireland (Stephens and Sullman, 2014). In case of the CAX, the factor "use of a vehicle to express anger" only included one item and was left out. We were able to develop reliable subscales for both instruments.

The results of this study stem from self-reported data collected by an online survey. Although internet use is increasing, limited internet use among subgroups in the population is a potential limitation. However, in Denmark, an extensive effort has been made to increase the use of the internet in the general population and it is mandatory to have an active email address through which information from public authorities is provided. Consequently, by $201592 \%$ of the population had an officially registered and accessible email address, eight out of ten had used the internet for shopping and 55\% of older people (75-89 years old) had been online within the past 3 months (Lauterbach, 2015). Thus although limited internet access is a potential bias we consider the effect to be limited. Similar to other panel based studies (Craig et al., 2013) the participants in the study were higher educated than the general population. However, as education level did not show a significant effect on anger expression in the regression analysis, this sample bias is probably negligible. A quota sampling approach is useful to increase representativeness on selected parameters, but even then it remains unknown if the participants are comparable to the general population on the unmeasured variables (Hays et al., 2015). However, such bias is not limited to online surveys. Regardless of the anonymity provided by an online survey the results of this study may be biased by social desirability (e.g. Lajunen and Summala, 2003) causing the respondents to be less likely to report social undesirable anger expressions. Finally, the cross-sectional nature of the study is a possible limitation, as all data was collected at the same point in time. Therefore, it is possible that short-term situational issues such as lack of concentration or recent unfortunate experiences related to road traffic anger influenced the answers provided by the participants. Such bias can be reduced based on a longitudinal design, which however was not possible in this study.

The comparison of DAX and CAX subscales showed that they are 
Table 8

DAX and CAX by self-reported traffic violations and anger expressions behaviours within the past 12 month.

\begin{tabular}{|c|c|c|c|c|c|c|c|c|c|c|}
\hline & & & \multicolumn{4}{|l|}{ DAX } & \multicolumn{4}{|l|}{ CAX } \\
\hline & & & Verbal & Physical & Constructive & Total aggression & Verbal & Physical & Constructive & Total aggression \\
\hline \multirow[t]{5}{*}{ Ticket for speeding } & Yes & Mean & 2.13 & 1.11 & 3.61 & 1.51 & 1.70 & 1.12 & 3.51 & 1.34 \\
\hline & & $N$ & 131 & 131 & 131 & 131 & 110 & 110 & 110 & 110 \\
\hline & No & Mean & 2.01 & 1.09 & 3.68 & 1.43 & 1.65 & 1.14 & 3.63 & 1.33 \\
\hline & & $N$ & 1486 & 1486 & 1486 & 1486 & 1140 & 1140 & 1140 & 1140 \\
\hline & & $F$-value & 3.30 & 0.18 & 0.75 & 4.24 & 0.51 & 0.17 & 1.26 & 0.02 \\
\hline \multirow[t]{5}{*}{ Ticket as cyclist } & Yes & Mean & 2.52 & 1.11 & 3.02 & 1.69 & 2.21 & 1.53 & 3.29 & 1.79 \\
\hline & & $N$ & 9 & 9 & 9 & 9 & 14 & 14 & 14 & 14 \\
\hline & No & Mean & 2.01 & 1.09 & 3.67 & 1.43 & 1.66 & 1.14 & 3.59 & 1.33 \\
\hline & & $N$ & 1241 & 1241 & 1241 & 1241 & 1519 & 1519 & 1519 & 1519 \\
\hline & & $F$-value & $4.15^{*}$ & 0.01 & $5.05^{*}$ & 3.20 & $7.37^{* *}$ & $8.57^{* *}$ & 1.04 & $10.79^{* * *}$ \\
\hline \multirow[t]{5}{*}{ Yelled at other road users } & Yes & Mean & 2.65 & 1.21 & 3.29 & 1.72 & 2.23 & 1.24 & 3.15 & 1.62 \\
\hline & & $N$ & 271 & 271 & 271 & 271 & 288 & 288 & 288 & 288 \\
\hline & No & Mean & 1.89 & 1.07 & 3.75 & 1.38 & 1.53 & 1.12 & 3.69 & 1.27 \\
\hline & & $N$ & 1346 & 1346 & 1346 & 1346 & 1245 & 1245 & 1245 & 1245 \\
\hline & & $F$-value & $276.41^{\text {kt.k.k. }}$ & $24.95^{\text {*x*kx}}$ & $64.00^{\text {*k*ken }}$ & $152.67^{k * * k}$ & $226.55^{* k * k}$ & $15.07^{* * * k}$ & $55.92^{* * * k}$ & $110.75^{* k * k}$ \\
\hline \multirow[t]{5}{*}{ Gave finger to other road users } & Yes & Mean & 2.61 & 1.19 & 3.32 & 1.70 & 2.12 & 1.27 & 3.09 & 1.59 \\
\hline & & $N$ & 212 & 212 & 212 & 212 & 195 & 195 & 195 & 195 \\
\hline & No & Mean & 1.93 & 1.08 & 3.73 & 1.40 & 1.60 & 1.12 & 3.66 & 1.30 \\
\hline & & $N$ & 1405 & 1405 & 1405 & 1405 & 1338 & 1338 & 1338 & 1338 \\
\hline & & $F$-value & $169.26^{\text {velcke }}$ & $12.07^{* *}$ & $40.74^{\text {trk*x }}$ & $99.21^{k * * *}$ & $83.18^{\text {*t2ktk }}$ & $15.77^{* \ldots * k}$ & $45.51^{\text {twotix }}$ & $55.80^{* * * *}$ \\
\hline
\end{tabular}

correlated as people scoring high on anger expression as cyclists also score high on anger expression as drivers and vice versa. In line with previous results on driver anger (Deffenbacher et al., 2016), this indicates influence from general trait-based anger on road traffic anger expression. However, the results also showed differences between anger expression among cyclists and drivers indicating that cyclist and driver anger expression are distinct phenomena triggered off by specific situations. More specifically, the comparison of DAX and CAX subscales showed that drivers score higher in verbal and total anger, which is in line with results of other studies showing that two-wheelers express less anger due to their perceived vulnerability (McGarva and Steiner, 2000). Further, results by Ellison-Potter et al. (2001) suggest that the lower degree of anonymity of cyclists compared to drivers contributes to lower levels of anger expression among cyclists compared to drivers. However, the result that cyclists and drivers express similar levels of physical aggression does not fit into this picture. It may reflect that cyclists in Denmark perceive a higher status as compared to cyclists in other countries and thus feel more ready to defend their rights against drivers also by physical expression despite being easily recognized. This interpretation is supported by the fact that Denmark in general (e.g. Fact sheet, 2015; Pucher and Buehler, 2008) and Copenhagen in particular (e.g. Copenhagenize, 2015; Fact sheet, 2015) are well established cycling communities in which less fear is associated with cycling compared to other countries (Chataway et al., 2014). It may also reflect that cyclists more often get in conflicts with other cyclists due to congestion on the cycle path as compared to other countries. The reported situations of physical aggression involving cyclists and/or drivers are however too few to analyse these situations in more detail. The interpretation is though supported by the results that cyclist anger expression is higher in Copenhagen, where we find a much higher level of cycling, than in the rest of Denmark (Fact sheet, 2015). Thus, the results of this study indicate that it is relevant to be aware of increased levels of anger expression among cyclists as an unintended consequence of increased cycling.

Results showed that DAX and CAX subscales are related to demographic variables. In line with previous results regarding driver anger (e.g. Dahlen and Ragan, 2004; González-Iglesias et al., 2012) male drivers and cyclists express more anger whereas women show more constructive behaviours. Though the gender differences were not very pronounced, we found more significant gender differences compared to the DAX applied in the UK and Ireland (Stephens and Sullman, 2014), which may be caused by the larger sample of our study. In general, however, the results support previous studies indicating a complex relationship between gender and anger expression (e.g. Deffenbacher et al., 2002; Herrero-Fernandéz, 2011). With regard to age, we found that older people show less verbal aggression and that people become more constructive with increasing age.

In line with previous results regarding the relationship between anger expression and level of education (e.g. Wickens et al., 2011; Smith and King, 2013) the results of this study point in different directions. We found indications of higher levels of anger expression among cyclists and drivers with lower education along with indications of comparably high levels of verbal anger expressions among more educated cyclists. The latter may reflect a higher level of exposure, as well-educated people are more likely to choose cycling as mode of transportation if possible (e.g. De Geus et al., 2008). Actually, when we included exposure and other factors in the regression analyses, education, income, and city size did not show a significant relation to driving and cycling anger expression, while exposure was clearly related to anger expression, which supports our interpretation. Another interesting finding of the regression analyses was the different effect of attitudes on driving and cycling aggression: While being enthusiastic about driving increases the level of driving anger, there was no significant relation between a positive cycling attitude and anger expression as cyclist. However, both driving and cycling stress contributed to driving and cycling anger expression, respectively. Further studies looking more into individual and situational characteristics are needed, but the present results indicate that the mechanisms and factors contributing to anger expression among cyclists and drivers differ, and that situational factors may be of key importance for anger expression among cyclists. However, the low explained variance of cycling anger expression in the regression analysis also point to the relevance of taking additional individual and situational factors into account than those considered in this study such as personality and infrastructural factors. 
Not surprisingly and in line with previous results (e.g. Precht et al., 2017) anger expression was related to violations. Interestingly, the relationship between anger expression and violations was also found among cyclists. No previous studies on this topic exist and further research is therefore highly recommended.

In this study a reliable instrument to measure cycling anger expression (CAX) was developed. Results showed similarities as well as differences regarding the level and nature of anger expression of drivers and cyclists. Further studies are needed to explore and explain these differences, particularly in the current context of supporting increased cycling.

\section{Acknowledgements}

The authors would like to acknowledge the financial support provided by the Danish Ministry of Transport, Building and Housing as well as by the Danish Road Safety Council.

\section{References}

Aldred, R., 2013. Incompetent or too competent? Negotiating everyday cycling identities in a motor dominated society. Mobilities 2, 252-271.

Björklund, G.M., 2008. Driver irritation and aggressive behaviour. Accid. Anal. Prev. 40, 1069-1077.

Bogdan, S.R., Mairean, C., Havârneanu, C.E., 2016. A meta-analysis of the association between anger and aggressive driving. Transp. Res. Part F 42, 350-364.

Carstensen, T.A., Ebert, A.K., 2012. Cycling cultures in northern europe: from golden age to renaissance. In: In: Parkin, J. (Ed.), Cycling and Sustainability 2012. Emerald Group Publishing Limited, Bingley, pp. 23-58.

Chataway, E.S., Kaplan, S., Nielsen, T.A.S., Prato, C.G., 2014. Safety perceptions and reported behavior related to cycling in mixed traffic: a comparison between Brisbane and Copenhagen. Transp. Res. Part F 23, 32-43.

Copenhagenize, 2015. The Copenhagenize Index 2015 of Bicycle Friendly Cities. http:// copenhagenize.eu/index/about.html.

Craig, M., Hays, R.D., Pickard, A.S., Cella, D., Revicki, D.A., Reeve, B.B., 2013. Comparison of US panel vendors for online surveys. J. Med. Internet Res. 15, e260.

Dahlen, E.R., Martin, R.C., Ragan, K., Kuhlman, M.M., 2005. Driving anger, sensation seeking, impulsiveness: and boredom proneness in the prediction of unsafe driving. Accid. Anal. Prev. 37, 341-348.

De Geus, B., De Bourdeaudhuij, I., Jannes, C., Meeusen, R., 2008. Psychosocial and environmental factors associated with cycling for transport among a working population. Health Educ. Res. 23, 697-708.

Deffenbacher, J.L., Lynch, R.S., Oetting, E.R., Yingling, D.A., 2001. Driving anger: correlates and a test of state-trait theory. Pers. Individ. Diff. 31, 1321-1331.

Deffenbacher, J.L., Lynch, R.S., Oetting, E.R., Swaim, R.C., 2002. The driving anger expression inventory: a measure of how people express their anger on the road. Behav. Res. Ther. 40, 717-737.

Deffenbacher, J.L., Stephens, A.N., Sullman, M.J.M., 2016. Driving anger as a psychological construct: twenty years of research using the Driving Anger Scale. Transp. Res. Part F 42, 236-247.

Dula, C.S., Geller, E.S., 2003. Risky, aggressive: or emotional driving: addressing the need for consistent communication in research. J. Safety Res. 34, 559-566.

Ellison-Potter, P., Bell, P., Deffenbacher, J., 2001. The effects of trait driving anger, anonymity: and aggressive stimuli on aggressive driving behavior. J. Appl. Soc. Psychol. 31, 431-443.

http://www.modelcenter.transport.dtu.dk/english/tu/hovedresultaterFact sheet, (2015).

Fong, G., Frost, D., Stansfeld, S., 2001. Road rage: a psychiatric phenomenon? Soc. Psychiatry Psychiatr. Epidemiol. 36, 277-286.

Fraine, G., Smith, S.G., Zinkiewicz, L., Chapman, R., Sheehan, M., 2007. At home on the road? Can drivers' relationships with their cars be associated with territoriality? J. Environ. Psychol. 27, 204-214.

Fruhen, L.S., Flin, R., 2015. Car driver attitudes: perceptions of social norms and aggressive driving behaviour towards cyclists. Accid. Anal. Prev. 83, 162-170.

González-Iglesias, B., Gómez-Fraguela, J.A., Luengo-Martín, M.A., 2012. Driving anger and traffic violations: gender differences. Transp. Res. Part F 15, 404-412.

Gwyther, H., Holland, C., 2014. Feelings of vulnerability and effects on driving behaviour -a qualitative study. Transp. Res. Part F 24, 50-59.

Harding, R.W., Morgan, F.H., Indermauer, D., Ferrante, A.M., Blagg, H., 1998. Road rage and the epidemiology of violence: something old something new. Stud. Crime Crime Prev. 7, 221-237.

Haustein, S., Nielsen, T.A.S., 2016. European mobility cultures: a survey-based cluster analysis across 28 European countries. J. Transp. Geogr. 54, 173-180.

Hays, R.D., Liu, H., Kapteyn, A., 2015. Use of Internet panels to conduct surveys. Behav. Res. 47, 685-690.

Heesch, K.C., Sahlqvist, S., Garrard, J., 2011. Cyclists' experiences of harassment from motorists: findings from a survey of cyclists in Queensland, Australia. Prev. Med. 53, 417-420.

Herrero-Fernandéz, D., 2011. Psychometric adaptation of the Driving Anger Expression Inventory in a Spanish sample: differences by age and gender. Transp. Res. Part F 14, 324-329.

Kaplan, S., Prato, C., 2016. "Them or us". Perceptions, cognitions, emotions, and overt behavior associated with cyclists and motorists sharing the road. Int. J. of Sustain. Transp. 3, 193-200.

Klein, W.M., Harris, P.R., Ferrer, R.A., Zajac, L.E., 2011. Feelings of vulnerability in response to threatening messages: effects of self-affirmation. J. Exp. Soc. Psychol. 47, 1237-1242.

Lajunen, T., Parker, D., 2001. Are aggressive people aggressive drivers? A study of the relationship between self-reported general aggressiveness, driver anger and aggressive driving. Accid. Anal. Prev. 33, 243-255.

Lajunen, T., Summala, H., 2003. Can we trust self-reports of driving?: effects of impression management on driver behaviour questionnaire. Transp. Res. Part F 6, 97-101.

Lauterbach, T., 2015. It-Anvendelse I Befolkningen 2015. (Retrieved from the Statistics Denmark website: www.dst.dk/Publ/ItBefolkning).

Lloyd, M., 2016. 'It's on video, every second of it': a microsociological analysis of cycle rage. Vis. Stud. 31, 206-220.

Lu, J., Xie, X., Zhang, R., 2013. Focusing on appraisals: how and why anger and fear influence driving risk perception. J. Saf. Res. 45, 65-73.

Matsumoto, D., Yoo, S.H., Chung, J., et al., 2010. The expression of anger across cultures. In: Potegal, M. (Ed.), International Handbook of Anger, pp. 125-137 (chapter 8).

McGarva, A.R., Steiner, M., 2000. Provoked driver aggression and status: a field study. Transp. Res. Part F 3, 167-179.

O'Brien, S., Tay, R., Watson, B., 2004. Situational factors contributing to the expression of aggression on the roads. IATSS Res. 28, 101-107.

Oja, P., Titze, S., Bauman, A., de Geus, B., Krenn, P., Reger-Nash, B., Kohlberger, T., 2011. Health benefits of cycling: a systematic review. Scand. J. Med. Sci. Sports 21, 496-509.

Parker, D., Lajunen, T., Summala, H., 2002. Anger and aggression among drivers in three European countries. Accid. Anal. Prev. 34, 229-235.

Precht, L., Keinath, A., Krems, J.F., 2017. Effects of driving anger on driver behavior -Results from naturalistic driving data. Transp. Res. Part F 45, 75-92.

FLOW Project, 2016. The role of walking and cycling in reducing congestion. A portfolio of measures. Brussels. http://www.h2020-flow.eu.

Rowden, P., Watson, B., Haworth, N., Lennon, A., Shaw, L., Blackman, R., 2016. Motorcycle riders' self-reported aggression when riding compared with car driving. Transp. Res. Part F 36, 92-103.

Shinar, D., Compton, R., 2004. Aggressive driving: an observational study of driver, vehicle: and situational variables. Accid. Anal. Prev. 36, 429-437.

Shinar, D., 1998. Aggressive driving: the contribution of the drivers and the situation. Transp. Res. Part F 1, 137-160.

Stephens, A.N., Sullman, M.J.M., 2014. Development of a short form of the driving anger expression inventory. Accid. Anal. Prev. 72, 169-176.

Sullman, M.J.M., 2006. Anger amongst New Zealand drivers. Transp. Res. Part F 9, 173-184.

Tainio, M., de Nazelle, A.J., Götschi, T., Kahlmeier, S., Rojas-Rueda, D., Nieuwenhuijsen, M.J., de Sá, T.H., Kelly, P., Woodcock, J., 2016. Can air pollution negate the health benefits of cycling and walking? Prev. Med. 87, 233-236.

Tillman, W.A., Hobbs, G.E., 1949. The accident-prone automobile driver. A study of the psychiatric and social background. Am. J. Psychiatry 106, 321-331.

Wickens, C.M., Mann, R.E., Stoduto, G., Ialomiteanu, A., Smart, R.G., 2011. Age group differences in self-reported aggressive driving perpetration and victimization. Transp. Res. Part F 14, 400-412.

Wickens, C.M., Mann, R.E., Wiesenthal, D.L., 2013. Addressing driver aggression: contributions from psychological science. Psychol. Sci. 22, 386-391.

Xia, T., Nitschke, M., Zhang, Y., Shah, P., Crabb, S., Hansen, A., 2015. Traffic-related air pollution and health co-benefits of alternative transport in Adelaide: South Australia. Environ. Int. 74, 281-290. 